\title{
EFEITOS DAS ESTRATÉGIAS DE APRENDIZAGEM AUTORREGULADA NA FORMAÇÃO DE INCONSCIENTE COLETIVO NO CONHECIMENTO DE CONTABILIDADE DE CUSTOS
}

\author{
THE EFFECTS OF LEARNING STRATEGIES SELF-REGULATED IN THE FORMATION OF \\ UNCONSCIOUS COLLECTIVE NOT KNOWLEDGE OF COST ACCOUNTING
}

\begin{abstract}
VINICIUS COSTA DA SILVA ZONATTO
Universidade Federal de Santa Maria (UFSM)

Titulação: Pós Doutor em Ciências Contábeis pela Universidade do Vale do Rio dos Sinos - UNISINOS

Doutor em Ciências Contábeis e Administração pela Universidade Regional de Blumenau - FURB Orcid: http://orcid.org/0000-0003-0823-6774 / E-mail: viniciuszonatto@gmail.com

Endereço: Universidade Federal de Santa Maria, Programa de Pós-graduação em Ciências Contábeis, Cidade Universitária, CCSH, Prédio 74C, Bairro Camobi, Santa Maria/RS, CEP: 97105-900

\section{THIAGO BRUNO DE JESUS SILVA}

Universidade Federal da Grande Dourados (UFGD)

Titulação: Doutor em Contabilidade pela Universidade Federal de Santa Catarina - UFSC

Orcid: http://orcid.org/0000-0002-1128-6601

E-mail: thiagobruno.silva@yahoo.com.br

\section{PATRINÊS APARECIDA FRANÇA ZONATTO}

Universidade Franciscana (UFN)

Titulação: Doutora em Administração pela Universidade do Vale do Itajaí - UNIVALI

Orcid: http://orcid.org/0000-0002-7518-0590

E-mail: patrineszonatto@gmail.com

JÉSSICA ANDRESSA KRAUSS

Universidade Regional de Blumenau (FURB)

Titulação: Graduanda em Enfermagem pela Fundação Universidade Regional de Blumenau - FURB

Orcid: http://orcid.org/0000-0003-0653-1577

E-mail: jessicakrauss96@gmail.com
\end{abstract}

Submissão: 01/04/2020. Revisão: 24/03/2021. Aceite: 30/06/2021. Publicação: 02/07/2021.

DOI: http://dx.doi.org/10.22277/rgo.v14i3.5356

\section{RESUMO}

Este artigo investiga o inconsciente de diferentes grupos de alunos quanto a aceitação dos métodos de custeio variável e absorção, observando-se os potenciais efeitos do nível de estratégias metacognitivas de aprendizagem autorregulada utilizadas pelos alunos. Pesquisa descritiva, com abordagem quantitativa, foi realizada junto a 186 alunos de Ciências Contábeis de três IES do Estado de Santa Catarina. Os resultados encontrados evidenciam que nem todos os estudantes participantes da pesquisa mudaram sua postura ao longo do curso. A formação docente contribuiu para que em todos os casos as médias relacionadas as diferentes concepções dos alunos aumentassem, indicando maior aderência aos preceitos do custeio variável após o curso da disciplina de contabilidade de custos, o que não foi observado entre

Este é um artigo publicado em acesso aberto (Open Access) sob a licença Creative Commons Attribution, que permite uso, distribuição e reprodução em qualquer meio, sem restrições desde que o trabalho original seja corretamente citado. 
Vinicius Costa da Silva Zonatto, Thiago Bruno de Jesus Silva, Patrinês Aparecida França Zonatto e Jéssica Andressa Krauss

todos os discentes da amostra. Esta mudança também não foi percebida de maneira uniforme no grupo de estudantes que já possui experiência profissional na área contábil, resultado que sugere a existência de um tipo específico de inconsciente coletivo relacionado ao uso de sistemas de contabilidade baseados na contabilidade financeira. Os achados desta pesquisa também indicam que há uma mudança de comportamento dos alunos quanto ao desenvolvimento de estratégias metacognitivas de aprendizagem autorregulada. Tais evidências sugerem que a formação de diferentes inconscientes coletivos está associada de maneira distinta a compreensão adequada dos conceitos relacionados aos métodos de custeio variável e por absorção, sendo que: formação docente, práticas de ensino, ênfase na abordagem dos conteúdos, experiência profissional na área contábil e estratégias metacognitivas de aprendizagem autorregulada são variáveis que contribuem para seu entendimento.

Palavras-chave: Inconsciente Coletivo. Estratégias de Aprendizagem. Autorregulação. Ensino de Ciências Contábeis. Contabilidade de Custos.

\begin{abstract}
This article investigates the unconscious of different groups of students regarding the acceptance of variable costing and absorption methods, observing the potential effects of the level of self-regulated metacognitive learning strategies used by the students. Descriptive research, with a quantitative approach, was carried out with 186 students of Accounting Sciences from three HEls in the State of Santa Catarina. The results show that not all the students participating in the research changed their posture during the course. The teacher training contributed to the fact that in all cases the averages related to the different conceptions of the students increased, indicating greater adherence to the precepts of variable costing after the course of the discipline of cost accounting, which was not observed among all the students in the sample. This change was also not perceived uniformly in the group of students who already have professional experience in the accounting area, a result that suggests the existence of a specific type of collective unconscious related to the use of accounting systems based on financial accounting. The findings of this research also indicate that there is a change in students' behavior regarding the development of metacognitive selfregulated learning strategies. Such evidence suggests that the formation of different collective unconscious is associated in a different way to the adequate understanding of the concepts related to variable costing and absorption methods, being that: teacher training, teaching practices, emphasis on content approach, professional experience in the area Accounting and metacognitive strategies of self-regulated learning are variables that contribute to their understanding.
\end{abstract}

Keywords: Collective Unconscious. Learning Strategies. Self-regulation. Accounting Science Teaching. Cost Accounting.

\title{
1 INTRODUÇÃO
}

Sob a psicologia analítica de Jung (1936), os indivíduos possuem um inconsciente que pode influenciar as suas decisões. Este inconsciente é abordado pela teoria como arquétipos. Arquétipo ou inconsciente de um próprio grupo pode ser caracterizado como uma espécie de aptidão para reproduzir constantemente as mesmas ideias míticas, se não as mesmas, pelo 
Efeitos das estratégias de aprendizagem autorregulada na formação de inconsciente coletivo no conhecimento de contabilidade de custos

menos parecidas (FABER; MAYER, 2009). Como resultado, os seres humanos que compartilham as mesmas ideias ou experiências mostram uma tendência a perceber significados comuns incorporados em um símbolo, mesmo em um nível inconsciente (LIU; WANG; ZHOU; NIE, 2020; BRADSHAW; STORM, 2013).

Em contabilidade, o inconsciente de grupo pode esclarecer diversas decisões ou escolhas realizadas por indivíduos, como o fato de se observar um acentuado descompasso entre a teoria e a prática relacionada ao uso de artefatos tradicionais ou modernos e o baixo grau de implementação nas organizações (GUERREIRO; CORNACHIONE JR.; SOUTES, 2011). Alguns estudos promoveram reflexões sobre as causas de aceitação por pessoas da área contábil de conceitos que já foram comprovados como ineficazes, como Guerreiro, Casado e Bio (2001; 2004), Slomski et al. (2003), Megliorini e Guerreiro (2004), Guerreiro, Frezatti e Casado (2006), Espejo et al. (2009), Costa, Cruz e Espejo (2011), Fernandes e Zonatto (2013) e Silva et al. (2015).

Os resultados encontrados nestes estudos têm divergido em alguns aspectos, em especial no que se refere a formação de inconsciente coletivo no contexto da contabilidade de custos. Uma possível explicação para tais achados, segundo Silva et al. (2015), pode estar relacionado a estrutura das disciplinas de contabilidade de custos, a forma como os docentes ministram a mesma e abordam seus conteúdos, elementos caracterizados como práticas de ensino, bem como as estratégias de aprendizagem dos alunos. Este último ainda pouco investigado nesta temática.

A partir do entendimento que a metacognição reconhece que a aprendizagem implica em tornar o discente autônomo, independente e, portanto, responsável por sua formação acadêmica (BOEKAERTS, CORNO, 2005; BECKER, 2011; 2013; SILVA et al., 2017; SILVA; BIAVATTI, 2018), este estudo busca compreender as razões que podem levar determinados indivíduos a persistirem com a aceitação de convicções mesmo quando são comprovadas ineficazes. Neste sentido, se caso o discente desenvolve durante o contexto educativo a pensar com "voz própria", característica da metacognição, este indivíduo reflete e não pode aceitar práticas/conceitos contábeis que já foram comprovados como inadequadas.

De acordo com Tuysozuglu (2011), as pesquisas educacionais realizadas nas últimas décadas têm defendido maior autonomia por parte dos discentes no processo de ensinoaprendizagem. As pessoas que são encorajadas a pensar autonomamente, que são mentalmente ativas e autoconfiantes, têm possibilidades de construir mais conhecimentos, podem discernir mais rapidamente do que os sujeitos que são desencorajados a pensar autonomamente (PIAGET, 1978). Papazoglou (2010) explica que uma aprendizagem incorporada no conhecimento consciente, no qual ao pensar com "voz própria" ao invés de aceitar passivamente realidades definidas pelos outros, o aluno desenvolve sua identidade e autonomia. Esta "voz própria" é definida como metacognição. Esta consciência deliberada permite fazer escolhas sobre o que vai ou não mudar, por exemplo.

Com base na teoria da metacognição, Zimmerman e Martinez-Ponz (1986) desenvolveram a metodologia self-regulated learning (SRL), que apresenta 14 estratégias metacognitivas de aprendizagem autorregulada. Estas estratégias auxiliam no desenvolvimento de aprendizagem autônoma, com sujeitos ativos, independente e responsável (NIIEMI et al. 2014). Uma vez que tais relacionamentos não foram investigados neste campo de estudo, busca-se com o desenvolvimento desta pesquisa responder as seguintes questões de estudo: Quais os efeitos do nível de uso das estratégias metacognitivas de aprendizagem autorregulada na formação de inconsciente coletivo quanto a aceitação dos métodos de custeio variável e por absorção no ensino de contabilidade de custos? 
Vinicius Costa da Silva Zonatto, Thiago Bruno de Jesus Silva, Patrinês Aparecida França Zonatto e Jéssica Andressa Krauss

Desta forma, o objetivo deste estudo consiste em investigar o inconsciente de diferentes grupos de alunos quanto a aceitação dos métodos de custeio variável e absorção, observando-se os potenciais efeitos do nível de estratégias metacognitivas de aprendizagem autorregulada utilizadas pelos alunos.

A pesquisa justifica-se pela importância do tema e a escassez de estudos sob a configuração proposta. $O$ nível de estratégia metacognitivas de aprendizagem autorregulada pode ser um fator relacionado a formação do inconsciente humano e que pode favorecer ou inibir a adoção de conceitos adequados de práticas gerenciais nas organizações. $\mathrm{O}$ ambiente de ensino é o local adequado para a promoção de reflexões sobre conceitos e a utilização das finalidades de ambos os métodos. Neste sentido, espera-se que este influencie a compreensão das diferenças entre tais métodos para fins gerenciais. Adicionalmente, esta pesquisa contribui por fornecer evidências de como outra variável como o nível de estratégias metacognitivas influenciam este contexto.

\section{FUNDAMENTAÇÃO TEÓRICA}

Esta seção apresenta a base teórica da pesquisa, que oferece suporte teórico para a realização do estudo. Inicia apresentando os conceitos relacionados aos arquétipos, o inconsciente coletivo e o ensino de contabilidade de custos. Na sequência, apresentam-se as concepções teóricas relacionadas as estratégias metacognitivas de aprendizagem autorregulada.

\subsection{ARQUÉTIPOS, INCONSCIENTE COLETIVO E O ENSINO DE CONTABILIDADE DE CUSTOS}

A contabilidade como uma atividade milenar possui uma base psíquica comum que é semelhante ao conceito de inconsciente próprio de grupo, o que constitui uma espécie de "inconsciente coletivo dos contadores" ou um repertório grupal de pessoas sujeitas à sua influência (GUERREIRO; CASADO; BIO, 2001). O inconsciente coletivo é uma figuração do mundo que representa a um só tempo a sedimentação multimilenar da experiência. Com o decorrer do tempo, foram-se definidos certos traços nessa configuração (JUNG, 1995). Estes traços são denominados de arquétipos.

Os arquétipos são impulsos psíquicos inconscientes que são impessoais, herdados por traços que norteiam e motivam os pensamentos, emoções e comportamentos muito antes de qualquer consciência se desenvolver (CHANG et al., 2013). Arquétipo ou inconsciente de um próprio grupo pode ser caracterizado como uma espécie de aptidão para reproduzir constantemente as mesmas ideias míticas, se não as mesmas, pelos menos próximas (FABER; MAYER, 2009). Como consequência, todos os seres humanos que compartilham as mesmas experiências mostram uma tendência a perceber significados comuns incorporados em um símbolo, mesmo em um nível inconsciente (LIU; WANG; ZHOU; NIE, 2020; BRADSHAW; STORM, 2013).

O inconsciente coletivo, por meio dos arquétipos, pode esclarecer diversas decisões ou escolhas realizadas por indivíduos, como o fato de se observar um acentuado descompasso entre a teoria e a prática relacionada ao uso de artefatos tradicionais ou modernos de contabilidade e o baixo grau de implementação de práticas gerenciais nas organizações (GUERREIRO, CORNACHIONE JR.; SOUTES, 2011). O papel do ensino em contabilidade é importante na mudança de comportamento, visto que este estimula a reflexão dos discentes (SILVA et al., 2017). A reflexão é fundamental para que os indivíduos possam conscientemente reavaliar tudo o que eles têm aceito inconscientemente, com vista a alterar o seu 
Efeitos das estratégias de aprendizagem autorregulada na formação de inconsciente coletivo no conhecimento de contabilidade de custos

comportamento conforme o caso (JUNG, 1995; GUERREIRO; CASADO; BIO, 2001; SLOMSKI; BATISTA; CARVALHO, 2003, GUERREIRO; BIO; CASADO, 2004; SILVA et al., 2015).

Neste sentido, Papazoglou (2010), pondera que uma aprendizagem incorporada no conhecimento consciente, no qual ao pensar com "voz própria", ao invés de aceitar passivamente realidades definidas pelos outros, o aluno desenvolve sua identidade e autonomia. Esta "voz própria" é definida como metacognição. Esta consciência deliberada permite fazer escolhas sobre o que vai ou não mudar, por exemplo. Assim, torna-se oportuno se observar os efeitos do nível de estratégias metacognitivas de aprendizagem autorregulada utilizadas pelos alunos na compreensão adequada de conceitos relacionados a contabilidade gerencial.

Especificamente no ensino de Contabilidade de Custos, dois conceitos têm sido utilizados em estudos anteriores para se avaliar os efeitos do inconsciente coletivo na compreensão de seus significados. Contudo, ao investigarem a aplicação das concepções teóricas de Jung (1936), sobre arquétipos e inconsciente coletivo, com a aceitação dos métodos de custeio variável e por absorção por alunos de diferentes cursos de graduação em Ciências Contábeis, Slomski et al. (2003), Guerreiro, Casado e Bio (2001; 2004) e Silva et al. (2015) encontraram resultados parcialmente divergentes.

Estes resultados fornecem evidências que contribuem para o entendimento de questões que afetam o ensino de contabilidade de custos, como também o entendimento de conceitos básicos ministrados nesta disciplina, os quais refletem na formação profissional do egresso do curso de Ciências Contábeis e também tenderão a influenciar suas escolhas quando da adoção de práticas de gestão (in)adequadas para fins gerenciais nas organizações. Tais investigações não têm observado os efeitos das estratégias metacognitivas de aprendizagem autorregulada nesta relação, lacuna teórica que se busca suprir com esta investigação.

Compreender os efeitos das práticas de ensino e as estratégias de aprendizagem adotadas pelos alunos contribui para o entendimento dos facilitadores da aprendizagem de conteúdos relacionados a contabilidade de custos, conhecimentos relevantes também demandados por organizações e a sociedade, para que se possa melhor promover a otimização dos recursos utilizados. Uma compreensão adequada da estrutura de custos de uma organização permite uma avaliação mais adequada de eficiência operacional e a identificação de oportunidades de melhoria. Por esta razão, torna-se relevante o entendimento adequado de tais conceitos.

Diante do exposto, tendo em vista o papel do ensino no desenvolvimento de estratégias metacognitivas, o que caracteriza na reflexão e mudança de comportamento dos discentes, torna-se oportuno investigar se o nível de estratégias metacognitivas de aprendizagem autorregulada influencia na formação de inconsciente coletivo quanto a aceitação dos métodos de custeio variável e por absorção no ensino de contabilidade de custos.

\subsection{ESTRATÉGIAS METACOGNITIVAS DE APRENDIZAGEM AUTORREGULADA}

A partir de 1970 houve discussões no campo teórico da psicologia sobre aspectos que permeiam a relação entre a memória e aprendizado, derivando o estudo da metacognição, definida como o domínio que o indivíduo possui sobre seu próprio conhecimento. Ainda na mesma década, esta definição é encorpada como o domínio dos processos e produtos cognitivos (FLAVELL, 1976). A metacognição está presente na literatura e ligada a um contexto educacional desde que o filósofo grego Sócrates afirmou que é preciso "conhecer a si mesmo" 
Vinicius Costa da Silva Zonatto, Thiago Bruno de Jesus Silva, Patrinês Aparecida França Zonatto e Jéssica Andressa Krauss

para ser sábio (GASSNER, 2009). Possibilita a pessoa pensar sobre como ela mesmo aprende. Assim, quando o indivíduo domina a forma como pensa e aprende, toma posse do conhecimento regulando e adequando sua aprendizagem de acordo ao que for preciso (DAGOSTINO, 2012).

A partir da metacognição foram iniciadas pesquisas lideradas por Barry Zimmerman para o entendimento da autorregulação ou Self Regulated Learn (SLR). Influenciado pelo paradigma construtivista, que tem o indivíduo como agente de seu aprendizado (XU et al., 2010), Zimmerman e Schunk (2001) afirmam que indivíduos autorregulados são persistentes, decididos, estratégicos e capazes de avaliar o seu progresso, diferentemente daqueles que são dependentes cognitivos, pouco autorregulados. A autorregulação da aprendizagem (SRL) enfatiza a autonomia e controle do discente a monitorar suas cognições, comportamentos e emoções orientadas para atingir as metas de aprendizagem (CHO; SHEN, 2013; DELEN; LIEW; WILSON, 2014; SILVA et al., 2017; SILVA, BIAVATTI, 2018).

Zimmerman e Martinez-Ponz (1986) desenvolveram 14 possíveis estratégias do aprendizado autorregulado. Para estes autores, o uso destas estratégias confere ao aluno um valioso ferramental, pois sua utilização está altamente correlacionada com os índices de sucesso acadêmico e com a opinião dos docentes acerca do seu grau de autorregulação em sala de aula. As estratégias são: a) autoavaliação; b) organização e transformação; c) estabelecimento de objetivos e planejamento; d) procura de informação; e) apontamentos; f) estrutura ambiental; g) autoconsequências; h) repetição e memorização; i) ajuda de professores; j) ajuda de pares próximos; k) ajuda de especialistas; I) revisão das anotações; m) revisão de testes; e n) revisão da bibliografia. O Quadro 2 apresenta uma síntese das definições de cada estratégia de aprendizagem, seguido de exemplos para sua melhor compreensão.

Quadro 2 - Estratégias de autorregulação da aprendizagem

\begin{tabular}{|c|c|c|c|}
\hline & Estratégias: & Definição: & Exemplos: Rosário (1999) \\
\hline 1 & Autoavaliação & $\begin{array}{l}\text { Declarações que indicam as avaliações dos } \\
\text { alunos sobre a qualidade ou progresso do seu } \\
\text { trabalho. }\end{array}$ & $\begin{array}{l}\text { "... verifiquei o meu trabalho } \\
\text { para ter a certeza que estava } \\
\text { bem". }\end{array}$ \\
\hline 2 & $\begin{array}{l}\text { Organização e } \\
\text { transformação }\end{array}$ & $\begin{array}{l}\text { Declarações que indicam as iniciativas dos } \\
\text { alunos para reorganizarem, melhorando-os, } \\
\text { os materiais de aprendizagem. }\end{array}$ & $\begin{array}{l}\text { “... faço sempre um esquema } \\
\text { antes de realizar os relatórios } \\
\text { das experiências de } \\
\text { química". }\end{array}$ \\
\hline 3 & $\begin{array}{c}\text { Estabelecimento de } \\
\text { objetivos e } \\
\text { planejamento }\end{array}$ & $\begin{array}{l}\text { Declarações indicando o estabelecimento de } \\
\text { objetivos educativos: planejamento e } \\
\text { conclusão de atividades relacionadas com } \\
\text { esses objetivos. }\end{array}$ & $\begin{array}{l}\text { “... começo a estudar duas } \\
\text { semanas antes do teste e fico } \\
\text { descansada". }\end{array}$ \\
\hline 4 & $\begin{array}{l}\text { Procura de } \\
\text { informação }\end{array}$ & $\begin{array}{l}\text { Declarações indicado os esforços dos alunos } \\
\text { para adquirir informações extra de fontes não } \\
\text { sociais quando enfrentaram uma tarefa } \\
\text { escolar. }\end{array}$ & $\begin{array}{l}\text { “... antes de começar um } \\
\text { trabalho, vou a biblioteca da } \\
\text { escola recolher o máximo de } \\
\text { informações sobre o tema". }\end{array}$ \\
\hline 5 & $\begin{array}{l}\text { Tomada de } \\
\text { apontamentos }\end{array}$ & $\begin{array}{l}\text { Declaração indicando os esforços para } \\
\text { registrar eventos ou resultados }\end{array}$ & $\begin{array}{l}\text { "...nas aulas sorvo o máximo } \\
\text { de apontamentos sobre o } \\
\text { que o professor dá". }\end{array}$ \\
\hline 6 & Estrutura ambiental & $\begin{array}{l}\text { Declarações indicando esforços para } \\
\text { selecionar ou alterar o ambiente físico ou } \\
\text { psicológico de modo a promover a } \\
\text { aprendizagem. }\end{array}$ & $\begin{array}{l}\text { “... para não me distrair, } \\
\text { isolo-me no quarto" ou “... } \\
\text { para me concentrar no que } \\
\text { estou fazendo, desligo o } \\
\text { som". }\end{array}$ \\
\hline
\end{tabular}


Efeitos das estratégias de aprendizagem autorregulada na formação de inconsciente coletivo no conhecimento de contabilidade de custos

\begin{tabular}{|c|c|c|c|}
\hline 7 & Autoconsequência & $\begin{array}{l}\text { Declarações indicando a imaginação ou a } \\
\text { concretização de recompensas ou punições } \\
\text { para sucessos ou fracassos escolares. }\end{array}$ & $\begin{array}{l}\text { "... se me der bem no teste, } \\
\text { compro uns chocolates". }\end{array}$ \\
\hline 8 & $\begin{array}{l}\text { Repetição e } \\
\text { memorização }\end{array}$ & $\begin{array}{l}\text { Declarações indicando as iniciativas e os } \\
\text { esforços dos alunos para memorizar o } \\
\text { material. }\end{array}$ & $\begin{array}{l}\text { "... na preparação de um } \\
\text { teste de física, escrevo } \\
\text { muitas vezes a fórmula, até } \\
\text { saber de cor". }\end{array}$ \\
\hline $9-11$ & $\begin{array}{l}\text { Procura de ajuda } \\
\text { social }\end{array}$ & $\begin{array}{l}\text { Declarações indicando as iniciativas e os } \\
\text { esforços dos alunos para procurarem ajuda } \\
\text { dos pares (9); professores (10); e adultos (11) }\end{array}$ & $\begin{array}{l}\text { "... se tenho dificuldades no } \\
\text { estudo peço ajuda ao meu } \\
\text { pai que é médico" }\end{array}$ \\
\hline $12-14$ & Revisão de dados & $\begin{array}{l}\text { Declarações indicando os esforços-iniciativas } \\
\text { dos alunos para relerem as notas (12); teste } \\
\text { (13); e livros de texto (14) a fim de se } \\
\text { prepararem para uma aula ou exercício } \\
\text { escritos. }\end{array}$ & $\begin{array}{l}\text { "... antes dos testes revejo } \\
\text { sempre os resumos da } \\
\text { matéria que fiz" ou "Para me } \\
\text { preparar para um teste } \\
\text { resolvo os enunciados dos } \\
\text { que já fiz". }\end{array}$ \\
\hline
\end{tabular}

Fonte: adaptado de Zimmerman e Martinez-Pons (1986) e Rosário (2001).

O aluno com grau desejável para autorregular sua aprendizagem tende a utilizar 14 categorias de estratégias autorregulatórias, a saber: autoavaliação, organização e transformação, planejamento e elaboração de metas, busca de informações, monitoramento e manutenção das anotações, estruturação do ambiente, autoconsequência, ensaio e memorização, pedido de ajuda aos pares, aos professores, à família, revisão de provas, de anotações e de textos e gerenciamento do tempo (ROSÁRIO, 2004). Além disso, alunos que tendem a apresentar sua aprendizagem autorregulada exibem maior rendimento acadêmico e melhores percepções de autoeficácia (ZIMMERMAN; MARTINEZ-PONS, 1986; SCHLEIFER; DULL, 2009).

Tuysuzoglu (2011), argumenta que o perfil do aluno autorregulado é de uma pessoa ativa e construtiva, que, portanto, estabelece metas para o seu aprendizado, acompanhando tal processo. Busca regular e controlar a sua cognição, motivação e comportamento, guiado e limitado por seus objetivos e características contextuais do ambiente. No campo das estratégias metacognitivas de aprendizagem autorregulada, alguns estudos se dedicaram a investigar o tema na educação contábil, como são os casos de Schleifer e Dull (2009), Byrne, Flood e Willis (2009), Ragosta (2010), Becker (2011; 2013), Lima Filho et al. (2015), Silva et al. (2017), Silva e Biavatti (2018), Aguiar (2019) e Butler, Church, King e Spencer (2021). Os resultados destes estudos fornecem evidências de que existem diferenças entre os alunos quanto a utilização de estratégias metacognitivas de aprendizagem autorregulada.

Embora os estudos anteriores abordem a estratégia de aprendizagem autorregulada, não consideraram que os resultados de suas pesquisas apontem que a aprendizagem pode desenvolver o discente a pensar com "voz própria", ser mais autônomo e independente, características da abordagem teórica da metacognição. Assim, diante de tais evidências e considerando-se a lacuna teórica de investigação, busca-se verificar a existência de diferenças estatisticamente significativas entre a formação de inconsciente coletivo de diferentes grupos de alunos quanto a aceitação dos métodos de custeio variável e absorção, observando-se os potenciais efeitos do nível de estratégias metacognitivas de aprendizagem autorregulada utilizadas pelos alunos. Tais motivações, estimulam a realização deste estudo.

\section{MÉTODO E PROCEDIMENTO DA PESQUISA}

Para tanto, foi realizada uma pesquisa descritiva, por meio de um levantamento, com abordagem quantitativa dos dados. A amostra da pesquisa compreendeu discentes do curso 
Vinicius Costa da Silva Zonatto, Thiago Bruno de Jesus Silva, Patrinês Aparecida França Zonatto e Jéssica Andressa Krauss

de Ciências Contábeis de três instituições de ensino superior, localizadas no Estado de Santa Catarina (Brasil). Os casos analisados foram selecionados de maneira intencional, sendo que estes possuem programas de pós-graduação na área de Administração, Ciências Contábeis e Turismo.

A escolha por estas instituições ocorreu em virtude de que a literatura tem indicado que características institucionais e de formação docente podem influenciar o ensino de contabilidade de custos, a ênfase abordada nestes conteúdos e a compreensão dos estudantes em relação as diferenças existentes sobre tais conceitos (SILVA et al., 2015). Foi assegurado as instituições que aceitaram voluntariamente participar da pesquisa o anonimato quanto a sua identificação, razão pela qual as instituições foram aqui nominadas como IES A, $B$ e C. Nas IES A e B foram alcançados todos os alunos matriculados nas disciplinas, respectivamente, 65 e 62 respondentes (em cada), já na IES C foram 59, dos 63 alunos regularmente matriculados.

A amostra do estudo compreendeu 186 discentes das três IES, em que não há predominância entre os gêneros e se cursou ou não a disciplina contabilidade de custos. Entre os respondentes, 41,54\% (IES A), 41, 94\% (IES B) e 59,32\% (IES C) possuem experiência profissional na área contábil, sendo que 33,85\% (IES A) e 35,59\% (IES C) têm entre 27 a 31 anos e $37,10 \%$ possuem entre 22 a 26 anos (IES B). A coleta de dados foi realizada por meio de aplicação de questionários in loco nas instituições pesquisadas. A Tabela 1 apresenta uma breve caracterização da amostra analisada.

Tabela 1 - Características da amostra estudada

\begin{tabular}{|c|c|c|c|c|c|c|}
\hline & \multicolumn{2}{|c|}{ IES A } & \multicolumn{2}{|c|}{ IES B } & \multicolumn{2}{|c|}{ IES C } \\
\hline & Quantidade & $\%$ & Quantidade & $\%$ & Quantidade & $\%$ \\
\hline Gênero & 65 & $100 \%$ & 62 & $100 \%$ & 59 & $100 \%$ \\
\hline Masculino & 33 & $50,77 \%$ & 31 & $50,00 \%$ & 28 & $47,46 \%$ \\
\hline Feminino & 32 & $49,23 \%$ & 31 & $50,00 \%$ & 31 & $52,54 \%$ \\
\hline Idade & 65 & $100 \%$ & 62 & $100 \%$ & 59 & $100 \%$ \\
\hline 17 a 21 anos & 10 & $15,38 \%$ & 6 & $9,68 \%$ & 8 & $13,56 \%$ \\
\hline 22 a 26 anos & 19 & $29,23 \%$ & 23 & $37,10 \%$ & 17 & $28,81 \%$ \\
\hline 27 a 31 anos & 22 & $33,85 \%$ & 21 & $33,87 \%$ & 21 & $35,59 \%$ \\
\hline Acima de 32 anos & 14 & $21,54 \%$ & 12 & $19,35 \%$ & 13 & $22,03 \%$ \\
\hline Experiência Profissional & 65 & $100 \%$ & 62 & $100 \%$ & 59 & $100 \%$ \\
\hline Em Contabilidade & 27 & $41,54 \%$ & 26 & $41,94 \%$ & 35 & $59,32 \%$ \\
\hline Em outras áreas & 25 & $38,46 \%$ & 25 & $40,32 \%$ & 15 & $25,42 \%$ \\
\hline Não possui & 13 & $20,00 \%$ & 11 & $17,74 \%$ & 9 & $15,25 \%$ \\
\hline Disciplinas de Custos & 65 & $100 \%$ & 62 & $100 \%$ & 59 & $100 \%$ \\
\hline Não cursou & 32 & $49,23 \%$ & 30 & $48,39 \%$ & 28 & $47,46 \%$ \\
\hline Cursaram as disciplinas & 33 & $50,77 \%$ & 32 & $51,61 \%$ & 31 & $52,54 \%$ \\
\hline
\end{tabular}

Fonte: dados da pesquisa.

Os respondentes participantes da pesquisa foram divididos em dois grupos de análise, sendo o primeiro formado por discentes que não cursaram a disciplina de contabilidade de custos, e o segundo grupo formado por discentes que já cursaram a referida disciplina. Além destas relações, foi observado ainda possíveis diferenças quanto a formação de um tipo de inconsciente específico em contabilidade, relacionado a diferenças na percepção de grupos de estudantes que possuem experiência profissional na área contábil. Tais procedimentos são convergentes aos adotados no estudo desenvolvido por Silva et al. (2015), para se avaliar diferenças entre as concepções observadas nesta pesquisa.

$O$ instrumento de coleta de dados foi dividido em três blocos de questões, sendo formado primeiramente por perguntas com o intuito de estabelecer uma caracterização dos 
Efeitos das estratégias de aprendizagem autorregulada na formação de inconsciente coletivo no conhecimento de contabilidade de custos

respondentes, como o gênero, idade, experiência profissional e se cursou ou não a disciplina contabilidade de custos. O segundo bloco (Tabela 2) foi formado por questões que buscaram capturar os aspectos relativos a concepção sobre os métodos de custeio variável e por absorção, utilizadas por Slomski et al. (2003) e Silva et al. (2015). O último bloco (Tabela 5) foi formado por questões utilizadas por Becker (2013), Lima Filho, Lima e Bruni (2015), Silva et al. (2017), Silva e Biavatti (2018), Aguiar (2019) e Butler, Church, King e Spencer (2021) que buscaram identificar o nível de utilização das estratégias de aprendizagem autorregulada.

Quadro 1 - Afirmações sobre concepções de custos

1) O valor da farinha de trigo utilizada na fabricação de bolo deverá ser considerado na medição do custo do bolo.

( ) Concordo plenamente ( ) Nem concordo, nem discordo ( ) Discordo plenamente

2) Para garantir a segurança das atividades da padaria, foi contratado o serviço de um vigilante. O valor pago a este vigilante não deverá ser considerado na medição do custo do bolo. ( ) Concordo plenamente ( ) Nem concordo, nem discordo ( ) Discordo plenamente

3) O valor do aluguel pago pelo prédio onde se encontra instalada a padaria deverá ser considerado na medição do custo do bolo.

( ) Concordo plenamente ( ) Nem concordo, nem discordo ( ) Discordo plenamente

4) O valor do salário pago à faxineira que cuida limpeza da padaria não deverá ser considerado na medição do custo do bolo.

( ) Concordo plenamente ( ) Nem concordo, nem discordo ( ) Discordo plenamente

5) O valor dos salários pagos aos padeiros que fabricam os bolos da padaria não deverá ser considerado na medição do custo do bolo.

( ) Concordo plenamente ( ) Nem concordo, nem discordo ( ) Discordo plenamente

6) Considerando que a padaria necessita de uma pessoa para supervisionar o trabalho de todos os outros funcionários (padeiros, vigilante e faxineira), o valor do seu salário deverá ser considerado na medição do custo do bolo.

( ) Concordo plenamente ( ) Nem concordo, nem discordo ( ) Discordo plenamente

7) O valor correspondente aos ovos utilizados na fabricação dos bolos da padaria não deverá ser considerado na medição do custo do bolo.

( ) Concordo plenamente ( ) Nem concordo, nem discordo ( ) Discordo plenamente

8) O valor do material gasto na embalagem de cada bolo da padaria deverá ser considerado na medição do custo do bolo.

( ) Concordo plenamente ( ) Nem concordo, nem discordo ( ) Discordo plenamente

Fonte: adaptado de Slomski et al. (2003).

As afirmações presentes no segundo bloco podem ser vistas na Figura 1. Para cada afirmação, o respondente deveria atribuir uma resposta entre concordo plenamente, nem concordo, nem discordo e discordo plenamente. Conforme se nota pela leitura das questões apresentadas, as colocações de números 3, 7, 9, 10 por se tratarem da aplicação de custos diretos e variáveis ao produto, poderão ser aplicáveis tanto ao custeio variável quanto ao custeio por absorção. Portanto, a determinação da aceitação de um ou outro método de custeio será dada pelas respostas das afirmativas de números $4,5,6$, e 8 que buscam identificar o tratamento que os entrevistados intuitivamente dão aos custos fixos.

As alternativas "concordo plenamente" e "discordo plenamente" indicam tendências diferentes dependendo da questão a que se refere. Na questão 3, a escolha da alternativa "concordo plenamente" indica entendimento de que os custos variáveis deverão ser alocados aos produtos. Na questão 4, a escolha da alternativa "concordo plenamente", indica a tendência ao custeio variável, a alternativa "discordo plenamente" por sua vez indica a tendência ao custeio por absorção. $\mathrm{Na}$ questão 5, a escolha da alternativa "concordo plenamente", indica a tendência ao custeio por absorção, a alternativa "discordo plenamente" por sua vez indica a tendência ao custeio variável. A questão 6 segue a mesma proposição que 
Vinicius Costa da Silva Zonatto, Thiago Bruno de Jesus Silva, Patrinês Aparecida França Zonatto e Jéssica Andressa Krauss

a questão 4. Na questão 7, a alternativa que indica que os custos variáveis devem ser considerados é "discordo plenamente". A questão 8 segue a mesma proposição da questão 5 . Já a questão 9 é com a mesma lógica da questão 7. Na última questão do segundo bloco do questionário, a lógica segue igual ao da questão 5.

Tabela 3 - Pesos esperados de resposta para cada um dos métodos de custeio analisados

\begin{tabular}{|c|c|c|c|c|c|c|c|c|c|c|}
\hline \multirow{2}{*}{$\begin{array}{c}\text { Tipo de } \\
\text { Custeio }\end{array}$} & \multicolumn{8}{|c|}{ Esperança de resposta para cada Questão } & \multirow{2}{*}{ Total } \\
\cline { 2 - 11 } & $\mathbf{3}$ & $\mathbf{4}$ & $\mathbf{5}$ & $\mathbf{6}$ & $\mathbf{7}$ & $\mathbf{8}$ & $\mathbf{9}$ & $\mathbf{1 0}$ & \\
\hline Variável & 1 & 3 & 3 & 3 & 3 & 3 & 3 & 1 & 20 \\
\hline Absorção & 1 & 1 & 1 & 1 & 3 & 1 & 3 & 1 & 12 \\
\hline
\end{tabular}

Fonte: adaptado de Slomski et al. (2003).

Slomski et al., (2003) explica que as questões foram elaboradas desta forma para evitar que uma possível sequência de escolha da mesma alternativa para várias questões e, desta forma, influenciassem o entrevistado a rever as suas respostas, o que prejudicaria a busca de respostas intuitivas prevista no estudo. Para tabulação dos dados, foram atribuídos pesos para cada uma das alternativas propostas em cada colocação. Primeiro, questões 3, 5, 7, 8, 9 e 10 : concordo o peso é 1 , nem concordo e nem discordo, o peso é 2 e discordo o peso é 3 . Na segunda, questões 4 e 6: concordo o peso é 3 , nem concordo e nem discordo o peso é 2 , discordo o peso é 1 .

A necessidade de se inverter os pesos das questões acima destacadas se deveu ao fato de que foram necessários ajustes no questionário realizado, para que se conseguisse determinar um peso total esperado para um respondente que considere o custeio variável, diferente de um pesquisado que considere o custeio por absorção. Desta forma, o discente que concorde plenamente com os procedimentos utilizados no custeio variável apresente o total de 20 pontos em seu questionário. Caso o pesquisado concorde com o custeio por absorção deverá apresentar o total de 12 pontos.

Para a análise dos dados, utilizaram-se os procedimentos quantitativos que abrangeram o uso de técnicas de análise estatística descritiva (média e desvio padrão) e comparação de médias (teste t) para a análise das concepções sobre os métodos de custeio de diferentes grupos de alunos. Para a análise do nível de utilização das estratégias de aprendizagem autorregulada, fez-se uso das técnicas de análise estatística descritiva (média, desvio padrão, mínimo e máximo), análise fatorial e de comparação de médias (teste $\mathrm{t}$ ). Tais procedimentos são convergentes aos adotadas por Silva et al. (2017) e Silva e Biavatti (2018). Os resultados desta análise são apresentados a seguir.

\section{ANÁLISE DOS DADOS}

Nesta seção são expostos e discutidos os resultados da pesquisa. Primeiramente, buscou-se identificar aspectos relativos à concepção sobre os métodos de custeio em três grupos distintos de alunos. Em seguida, identificou-se o nível de utilização das estratégias metacognitivas de aprendizagem autorregulada. Por último, observou-se os potenciais efeitos do nível de estratégias metacognitivas de aprendizagem autorregulada utilizadas pelos alunos.

\subsection{CONCEPÇÃO SOBRE OS MÉTODOS DE CUSTEIO}

A Tabela 2 apresenta os resultados sobre a concepção dos métodos de custeio formados por toda a amostra de alunos, divididos entre os que não estudaram a disciplina de contabilidade de custos em suas IES (grupo 1) e os que já estudaram (grupo 2). 
Efeitos das estratégias de aprendizagem autorregulada na formação de inconsciente coletivo no conhecimento de contabilidade de custos

Tabela 2 - Resultados sobre a concepção dos métodos de custeio de diferentes grupos

\begin{tabular}{clcccccc}
\hline \multirow{2}{*}{ IES } & \multicolumn{1}{c}{ Grupos } & N & Média & $\begin{array}{c}\text { Desvio } \\
\text { Padrão }\end{array}$ & $\begin{array}{c}\text { Erro Padrão } \\
\text { da Média }\end{array}$ & T & $\begin{array}{c}\text { Sig (2 } \\
\text { extremidades) }\end{array}$ \\
\hline \multirow{2}{*}{ IES A } & Grupo 01 (Não Estudaram) & 32 & 12,8437 & 0,9540 & 0,1686 & 12,057 & 0,000 \\
& Grupo 02 (Estudaram) & 33 & 16,1818 & 1,2613 & 0,2195 & 12,005 & 0,000 \\
\hline \multirow{2}{*}{ IES B } & Grupo 01 (Não Estudaram) & 30 & 13,1333 & 1,6760 & 0,3060 & 9,130 & 0,000 \\
& Grupo 02 (Estudaram) & 32 & 16,7812 & 1,4532 & 0,2568 & 9,173 & 0,000 \\
\hline \multirow{2}{*}{ IES C } & Grupo 01 (Não Estudaram) & 28 & 13,2857 & 1,0837 & 0,2048 & 11,218 & 0,000 \\
& Grupo 02 (Estudaram) & 31 & 17,6129 & 1,8198 & 0,3268 & 10,945 & 0,000 \\
\hline
\end{tabular}

Fonte: dados da pesquisa.

Os resultados encontrados indicam uma estatística $t$ com nível de significância menores que 0,05 , assim rejeita-se a hipótese nula de igualdade de concepções entre os diferentes grupos. Portanto, existem diferenças entre as médias dos grupos 1 e 2 das três instituições. Nestas instituições de ensino os alunos que ainda não estudaram a disciplina de contabilidade de custos parecem assumir uma postura mais aderente ao custeio por absorção. Já os alunos que estudaram esta disciplina assumem médias mais aderentes ao custeio variável. Tais evidências sugerem que as médias aumentam gradativamente de acordo a evolução do aluno no curso.

Estes achados se assemelham aos encontrados por Silva et al. (2015). Contudo, diferem parcialmente dos resultados encontrados por Slomski et al. (2003). Considerando-se as características destas disciplinas e a formação dos docentes que ministraram as disciplinas de contabilidade de custos nas IES A, B e C, em que em todos os casos são docentes com formação em nível de doutorado, é possível se admitir que a qualificação docente exerce influência na forma como estes profissionais ministram estes conceitos, o que pode contribuir para uma melhor compreensão de suas diferenças. Por tratar-se de docentes vinculados a pós-graduação stricto sensu, ou seja, professores pesquisadores, é possível que estes profissionais enfatizem além das diferenças entre ambos os métodos, sua adequação a abordagem gerencial nas organizações.

Estes achados são condizentes a afirmação do Jung (1995) quanto as concepções teóricas da psicologia analítica, que afirma que a reflexão é fundamental para que os indivíduos reavaliem conscientemente tudo o que eles têm aceitado inconscientemente, com vistas a mudar seu comportamento. Estes resultados podem indicar que os alunos possuem uma aprendizagem que implica em torná-lo autônomo (independente), e, portanto, responsável por sua formação acadêmica. No entanto, tais resultados também revelam que determinados indivíduos não conseguem desprender-se das concepções teóricas relacionadas ao custeio por absorção, mesmo já tendo cursado a disciplina de contabilidade de custos. Tais evidências, segundo Silva et al. (2015), estão relacionadas a outros fatores que podem explicar a formação de um tipo de inconsciente específico, como a experiência profissional destes indivíduos em atividades relacionadas a contabilidade financeira.

Assim, a fim de se investigar tais relações, apresenta-se na Tabela 3 os resultados encontrados sobre a análise de diferenças quanto a concepção dos métodos de custeio formados por toda a amostra de alunos que possuem experiência profissional na área contábil, divididos entre aqueles que não estudaram a disciplina de contabilidade de custos (grupo 1) e os que estudaram (grupo 2). Nesta análise, foram excluídos da amostra aqueles discentes que possuem experiência profissional em outra área que não a contabilidade. Tal procedimento é convergente ao adotado por Silva et al. (2015) para avaliar a existência dos efeitos de um tipo específico de inconsciente coletivo sobre tais percepções. 
Vinicius Costa da Silva Zonatto, Thiago Bruno de Jesus Silva, Patrinês Aparecida França Zonatto e Jéssica Andressa Krauss

Tabela 3 - Resultados sobre a concepção dos métodos de custeio de diferentes grupos com estudantes que possuem experiência profissional especificamente na área contábil

\begin{tabular}{clcccccc}
\hline \multirow{2}{*}{ IES } & \multicolumn{1}{c}{ Grupos } & N & Média & $\begin{array}{c}\text { Desvio } \\
\text { Padrão }\end{array}$ & $\begin{array}{c}\text { Erro Padrão } \\
\text { da Média }\end{array}$ & T & $\begin{array}{c}\text { Sig (2 } \\
\text { extremidades) }\end{array}$ \\
\hline \multirow{2}{*}{ IES A } & Grupo 01 (Não Estudaram) & 19 & 12,3160 & 0,5824 & 0,1336 & 4,814 & 0,002 \\
& Grupo 02 (Estudaram) & 8 & 15,7500 & 1,9821 & 0,7008 & 7,028 & 0,000 \\
\hline \multirow{2}{*}{ IES B } & Grupo 01 (Não Estudaram) & 18 & 13,1110 & 1,9063 & 0,4493 & 5,260 & 0,000 \\
& Grupo 02 (Estudaram) & 8 & 16,7500 & 1,4880 & 0,5261 & 4,772 & 0,000 \\
\hline \multirow{2}{*}{ IES C } & Grupo 01 (Não Estudaram) & 17 & 13,1180 & 0,9926 & 0,2407 & 9,921 & 0,000 \\
& Grupo 02 (Estudaram) & 18 & 18,1110 & 1,8752 & 0,4420 & 9,759 & 0,000 \\
\hline
\end{tabular}

Fonte: dados da pesquisa.

Os resultados apresentados na Tabela 3 evidenciam que a mudança nas concepções dos alunos das IES A, B e $C$ que possuem experiência profissional em contabilidade ocorre de maneira distinta. Na IES A os resultados da média encontrada são menores que a média geral analisada na Tabela 2, o que revela que nem todos conseguem desprender-se dos conceitos relacionados ao custeio por absorção, mesmo após cursarem esta disciplina. Tais resultados indicam a existência de um inconsciente próprio que contempla a influência de experiências anteriores relacionadas a contabilidade financeira. As médias encontradas nas demais IES (B e C) são mais aderentes as concepções do custeio variável, porém em intensidades diferentes. Estes resultados são reforçados pela análise do desvio padrão observado em todos os grupos de alunos que cursaram a disciplina de contabilidade de custos nas três instituições pesquisadas, os quais se aproximaram de 2 pontos.

Desta forma, percebe-se que alguns destes alunos, mesmo após estudarem a disciplina de contabilidade de custos, permanecem assumindo uma postura mais aderente ao custeio por absorção. Estes resultados corroboram parcialmente com os encontrados no estudo desenvolvido por Silva et al. (2015), que encontraram resultados conflitantes em duas amostras distintas e divergentes das evidências anteriormente apresentadas por Santos (1976) e Guerreiro, Casado e Bio (2001; 2004). Neste caso, percebe-se que os discentes pertencentes a este grupo específico (aqueles que trabalham em área contábil) não possuem um tipo predominante de inconsciente coletivo, sendo alguns alunos influenciados tanto pelas condições de aprendizagem (ensino de contabilidade de custos), como também por suas experiências profissionais anteriores na área contábil.

Em relação ao grupo de alunos que apresentaram maior aderência aos preceitos do conceito variável, observa-se que estes resultados podem estar relacionados a uma aprendizagem que implica em torna-lo autônomo, independente e, portanto, responsável por sua formação acadêmica. Nestes casos, os resultados sugerem que estes indivíduos tendem a refletir sobre as diferenças entre tais conceitos, compreendendo melhor suas limitações e potenciais contribuições quando utilizados para fins gerenciais. Tais evidências sugerem a adoção de níveis diferenciados de estratégias metacognitivas de aprendizagem autorregulada por parte dos alunos participantes da pesquisa. Estas evidências são investigadas a seguir.

\subsection{ESTRATÉGIAS METACOGNITIVAS DE APRENDIZAGEM AUTORREGULADA}

Na Tabela 4 são apresentados os resultados da análise das estratégias metacognitivas de aprendizagem autorregulada utilizadas pelos estudantes participantes da pesquisa, para enfrentar suas atividades acadêmicas. 
Efeitos das estratégias de aprendizagem autorregulada na formação de inconsciente coletivo no conhecimento de contabilidade de custos

Tabela 4 - Estratégias de Aprendizagem Autorregulada (SRL) dos discentes pesquisados

\begin{tabular}{|c|c|c|c|c|c|c|c|c|c|c|c|c|c|}
\hline \multicolumn{2}{|c|}{ IES A } & \multirow{2}{*}{$\frac{\text { E1 }}{6,1231}$} & \multirow{2}{*}{$\frac{\text { E2 }}{4,3385}$} & \multirow{2}{*}{$\frac{\text { E3 }}{5,4769}$} & \multirow{2}{*}{$\frac{E 4}{6,0923}$} & \multirow{2}{*}{$\frac{\text { E5 }}{6,1846}$} & \multirow{2}{*}{$\frac{\text { E6 }}{4,4769}$} & \multirow{2}{*}{$\frac{\text { E7 }}{2,0462}$} & \multirow{2}{*}{$\begin{array}{c}\text { E8 } \\
5,0154\end{array}$} & \multirow{2}{*}{$\begin{array}{c}\text { E9 } \\
5,9538\end{array}$} & \multirow{2}{*}{$\frac{\text { E10 }}{5,9538}$} & \multirow[t]{2}{*}{ MG } & \multirow[t]{2}{*}{ DP } \\
\hline$\pi$ & $M$ & & & & & & & & & & & & \\
\hline 응 유 & $\mathrm{DP}$ & 0,7397 & 1,5338 & 1,1740 & 0,7851 & 0,8080 & 1,8465 & 1,6339 & 1,2561 & 0,3274 & 0,3721 & \multirow{3}{*}{5,1662} & \multirow{3}{*}{1,6838} \\
\hline ᄃ & $\mathrm{Mn}$ & 5 & 1 & 3 & 4 & 5 & 1 & 1 & 3 & 4 & 4 & & \\
\hline & $\mathrm{Mx}$ & 7 & 7 & 7 & 7 & 7 & 7 & 7 & 7 & 7 & 7 & & \\
\hline \multirow{4}{*}{ 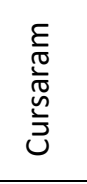 } & $M$ & 6,0606 & 5,0909 & 6,0606 & 6,0909 & 6,8485 & 6,0303 & 2,8788 & 6,1818 & 6,0303 & 6,0303 & \multirow{4}{*}{5,7303} & \multirow{4}{*}{1,2487} \\
\hline & $\mathrm{DP}$ & 0,5556 & 0,6307 & 0,5556 & 0,5790 & 0,3641 & 0,1741 & 1,8330 & 0,3917 & 0,1741 & 0,1741 & & \\
\hline & $\mathrm{Mn}$ & 5 & 4 & 5 & 5 & 6 & 6 & 1 & 6 & 6 & 6 & & \\
\hline & $M x$ & 7 & 7 & 7 & 7 & 7 & 7 & 7 & 7 & 7 & 7 & & \\
\hline \multirow{4}{*}{  } & M & 6,1875 & 3,5625 & 4,8750 & 6,0938 & 5,5000 & 2,8750 & 1,1875 & 3,8125 & 5,8750 & 5,8750 & \multirow{4}{*}{4,5844} & \multirow{4}{*}{1,8685} \\
\hline & $\mathrm{DP}$ & 0,8958 & 1,7949 & 1,3380 & 0,9625 & 0,5080 & 1,3380 & 0,7378 & 0,3966 & 0,4212 & 0,4919 & & \\
\hline & $\mathrm{Mn}$ & 5 & 1 & 3 & 4 & 5 & 1 & 1 & 3 & 4 & 4 & & \\
\hline & $\mathrm{Mx}$ & 7 & 5 & 6 & 7 & 6 & 4 & 4 & 4 & 6 & 6 & & \\
\hline \multicolumn{2}{|c|}{ IES B } & E1 & E2 & E3 & E4 & E5 & E6 & E7 & E8 & E9 & E10 & MG & DP \\
\hline \multirow{4}{*}{$\begin{array}{l}\frac{\pi}{0} \\
\frac{0}{0} \\
0 \\
0 \\
0\end{array}$} & $M$ & 6,1452 & 4,4194 & 5,5484 & 6,1774 & 6,0806 & 4,4516 & 3,0161 & 5,1613 & 6,0161 & 5,9355 & & \\
\hline & DP & 0,8463 & 1,7230 & 1,3266 & 0,8125 & 0,7531 & 1,9221 & 1,8242 & 1,3452 & 0,2212 & 0,5393 & & \\
\hline & $\mathrm{Mn}$ & 4 & 1 & 3 & 5 & 5 & 1 & 1 & 3 & 5 & 3 & 8 & 1 \\
\hline & $\mathrm{Mx}$ & 7 & 7 & 7 & 7 & 7 & 7 & 7 & 7 & 7 & 7 & & \\
\hline & $\mathrm{M}$ & 6,1563 & 5,3750 & 6,2813 & 6,2188 & 6,6250 & 6,0313 & 4,2500 & 6,3750 & 6,0313 & 6,0313 & & \\
\hline$\frac{\pi}{\pi}$ & $\mathrm{DP}$ & 0,7666 & 0,7513 & 0,6832 & 0,7064 & 0,4919 & 0,3095 & 1,3198 & 0,5536 & 0,3095 & 0,4004 & & \\
\hline$\stackrel{气}{5}$ & $\mathrm{Mn}$ & 4 & 4 & 5 & 5 & 6 & 5 & 1 & 5 & 5 & 5 & 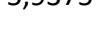 & 0 \\
\hline & $\mathrm{Mx}$ & 7 & 7 & 7 & 7 & 7 & 7 & 7 & 7 & 7 & 7 & & \\
\hline$\varepsilon$ & $\mathrm{M}$ & 6,1333 & 3,4000 & 4,7667 & 6,1333 & 5,5000 & 2,7667 & 1,7000 & 3,8667 & 6,0000 & 5,8333 & & \\
\hline $2 \frac{\bar{T}}{\pi}$ & $\mathrm{DP}$ & 0,9371 & 1,8864 & 1,4065 & 0,9371 & 0,5085 & 1,4065 & 1,2905 & 0,3457 & 0,0000 & 0,6477 & & \\
\hline$\stackrel{气}{5}$ & $\mathrm{Mn}$ & 5 & 1 & 3 & 5 & 5 & 1 & 1 & 3 & 6 & 3 & 0 & 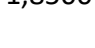 \\
\hline & $\mathrm{Mx}$ & 7 & 5 & 6 & 7 & 6 & 4 & 4 & 4 & 6 & 6 & & \\
\hline IES & & E1 & E2 & E3 & E4 & E5 & E6 & E7 & E8 & E9 & E10 & MG & DP \\
\hline & M & 5,8814 & 4,0678 & 5,2542 & 5,8475 & 6,2542 & 4,4407 & 2,5424 & 5,0169 & 5,9322 & 5,5254 & & \\
\hline 응ㅇㅁ & DP & 0,6717 & 1,6280 & 1,2261 & 0,6383 & 0,8827 & 2,0280 & 1,7842 & 1,1521 & 0,3650 & 0,8581 & & \\
\hline & $\mathrm{Mn}$ & 5 & 1 & 3 & 5 & 5 & 1 & 1 & 3 & 4 & 4 & 103 & כ2000 \\
\hline & $M x$ & 7 & 7 & 7 & 7 & 7 & 7 & 7 & 7 & 7 & 7 & & \\
\hline$\varepsilon$ & $\mathrm{M}$ & 5,9032 & 4,9355 & 5,9355 & 5,9032 & 6,9677 & 6,0323 & 3,9355 & 5,9677 & 5,9677 & 5,9355 & & \\
\hline$\frac{\pi}{\pi}$ & DP & 0,4729 & 0,5122 & 0,4424 & 0,3962 & 0,1796 & 0,1796 & 1,3889 & 0,4069 & 0,3145 & 0,4424 & 7484 & 9457 \\
\hline$\stackrel{\text { ڤ }}{3}$ & $\mathrm{Mn}$ & 5 & 4 & 5 & 5 & 6 & 6 & 1 & 4 & 5 & 4 & & \\
\hline & $\mathrm{Mx}$ & 7 & 7 & 7 & 7 & 7 & 7 & 7 & 7 & 7 & 7 & & \\
\hline$\varepsilon$ & M & 5,8571 & 3,1071 & 4,5000 & 5,7857 & 5,4643 & 2,6786 & 1,0000 & 3,9643 & 5,8929 & 5,0714 & & \\
\hline $2 \frac{\bar{T}}{20}$ & $\mathrm{DP}$ & 0,8483 & 1,8923 & 1,3744 & 0,8325 & 0,6372 & 1,6342 & 0,0000 & 0,6929 & 0,4163 & 0,9786 & & \\
\hline$\stackrel{5}{5}$ & $\mathrm{Mn}$ & 5 & 1 & 3 & 5 & 5 & 1 & 1 & 3 & 4 & 4 & 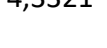 & 1,0050 \\
\hline$u$ & $M x$ & 7 & 5 & 6 & 7 & 7 & 6 & 1 & 6 & 6 & 6 & & \\
\hline
\end{tabular}

Legenda: E1 - estratégia de autoavaliação; E2 - estratégia de organização e transformação; E3 - estratégia de estabelecimento de objetivos e planejamento; E4 - estratégia de procura de informação; E5 - estratégia de tomada de apontamentos; E6 - estratégia de estrutura ambiental; E7 - estratégia autoconsequência; E8 estratégia de repetição e memorização; E9 - estratégia de procura de ajuda social; E10 - estratégia de revisão de dados; $\mathrm{M}$ - média; MG - média geral; DP - desvio padrão; Mn - mínimo; Mx - máximo.

Fonte: dados da pesquisa.

Como pode-se verificar a partir dos resultados apresentados na Tabela 4, em todos os casos, os estudantes que já cursaram a disciplina contabilidade de custos possuem média maior de utilização das estratégias metacognitivas de aprendizagem autorregulada, comparativamente aos alunos que não cursaram. Destaca-se que a maior média foi observada entre os estudantes que cursaram a disciplina da IES B. Já a menor foi para os estudantes que 
Vinicius Costa da Silva Zonatto, Thiago Bruno de Jesus Silva, Patrinês Aparecida França Zonatto e Jéssica Andressa Krauss

não cursaram a disciplina na IES C. Estes resultados fornecem evidências que podem indicar motivos pelos quais os indivíduos refletem e não aceitam práticas/conceitos contábeis que já foram comprovados como inadequados para fins gerenciais, uma vez que tanto sob a perspectiva da psicologia analítica de Jung (1936), quanto pela abordagem metacognitiva de aprendizagem autorregulada proposta por Zimmerman e Schunk (2001), os discentes, ao estudarem e evoluírem na escala educativa, adquirem novos conhecimentos que são capazes de modificar suas crenças.

De acordo com Silva e Biavatti (2018), isto ocorre porque os alunos, ao evoluírem na escala educativa, vão experimentando novos métodos de ensino que the são apresentados, o que lhes permite melhor julgar os conceitos aprendidos. Conforme explicam Black (2012) e Cootzee e Schmulian (2012), os docentes também se movimentam no sentido de apresentar e introduzir novas metodologias de ensino focadas no aluno. Tal estratégia visa estimular à formação de profissionais mais críticos, capazes de compreender questões mais filosóficas e diferenças conceituais entre os aspectos de ensino que lhe são apresentados, como no caso desta pesquisa, as diferenças das metodologias de custeio investigadas.

Em relação as estratégias, as menos utilizadas foram a organização e a transformação (E2) e a estratégia da autoconsequência (E7) para toda as IES. Essas estratégias estão divididas entre as fases de planejamento e autorreflexão, respectivamente. Demetriou (2000) explica que a participação ativa do estudante exige consciência dos objetivos a serem alcançados, reconhecimento da ação a se alcançar, separação e estabelecimento dos recursos internos e externos para a execução da ação, avaliação do nível de realização e alteração dos procedimentos utilizados se o resultado não for o previsto. Este resultado também foi encontrado por Lima Filho, Lima e Bruni (2015), Silva et al. (2017) e Silva e Biavatti (2018).

A Tabela 5 apresenta os resultados da análise fatorial realizada, com o intuito de resumir os dados analisados, e verificar se há diferenças entre a adoção de Estratégias Metacognitivas de Aprendizagem Autorregulada (EMC), na amostra analisada. Assim, quando formado mais de um fator, pode-se inferir que há componentes distintos que representam a adoção e uso de padrões distintos de EMC naquela amostragem, o que reforça a importância da análise de sua influência nas concepções desenvolvidas pelos estudantes.

Tabela 5 - Análise de Componente Principal para as Estratégias de Aprendizagem Autorregulada (SRL)

\begin{tabular}{|c|c|c|c|c|c|c|}
\hline \multirow{2}{*}{$\begin{array}{c}\text { IES A } \\
\text { Componente }\end{array}$} & \multicolumn{3}{|c|}{ Valores próprios iniciais } & \multicolumn{3}{|c|}{$\begin{array}{l}\text { Somas extraídas dos carregamentos } \\
\text { quadráticos }\end{array}$} \\
\hline & Total & \% de variância & $\%$ cumulativa & Total & \% de variância & $\%$ cumulativa \\
\hline 1 & 5,479 & 54,791 & 54,791 & 5,479 & 54,791 & 54,791 \\
\hline 2 & 1,848 & 18,481 & 73,272 & 1,848 & 18,481 & 73,272 \\
\hline 3 & 891 & 8,912 & 82,185 & & & \\
\hline 4 & ,747 & 7,468 & 89,653 & & & \\
\hline 5 & ,663 & 6,628 & 96,280 & & & \\
\hline 6 & ,200 & 2,004 & 98,285 & & & \\
\hline 7 & ,102 & 1,016 & 99,301 & & & \\
\hline 8 & ,068 & 676 & 99,977 & & & \\
\hline 9 & ,002 & ,019 & 99,995 & & & \\
\hline 10 &, 000 & ,005 & 100,000 & & & \\
\hline IES B & \multicolumn{3}{|c|}{ Valores próprios iniciais } & \multicolumn{3}{|c|}{$\begin{array}{l}\text { Somas extraídas dos carregamentos } \\
\text { quadráticos }\end{array}$} \\
\hline Componente & Total & \% de variância & $\%$ cumulativa & Total & \% de variância & $\%$ cumulativa \\
\hline 1 & 5,487 & 54,872 & 54,872 & 5,487 & 54,872 & 54,872 \\
\hline 2 & 1,790 & 17,897 & 72,769 & 1,790 & 17,897 & 72,769 \\
\hline 3 & 1,259 & 12,594 & 85,364 & 1,259 & 12,594 & 85,364 \\
\hline
\end{tabular}


Efeitos das estratégias de aprendizagem autorregulada na formação de inconsciente coletivo no conhecimento de contabilidade de custos

\begin{tabular}{|c|c|c|c|c|c|c|}
\hline 4 & 609 & 6,092 & 91,456 & & & \\
\hline 5 & ,423 & 4,226 & 95,681 & & & \\
\hline 6 & 192 & 1,924 & 97,605 & & & \\
\hline 7 & 144 & 1,445 & 99,050 & & & \\
\hline 8 & ,081 & 808 & 99,858 & & & \\
\hline 9 & ,008 & 081 & 99,939 & & & \\
\hline 10 &, 006 &, 061 & 100,000 & & & \\
\hline IES C & \multicolumn{3}{|c|}{ Valores próprios iniciais } & \multicolumn{3}{|c|}{$\begin{array}{c}\text { Somas extraídas dos carregamentos } \\
\text { quadráticos }\end{array}$} \\
\hline Componente & Total & \% de variância & $\%$ cumulativa & Total & \% de variância & $\%$ cumulativa \\
\hline 1 & 6,156 & 61,560 & 61,560 & \multirow{10}{*}{$\begin{array}{l}6,156 \\
1,958\end{array}$} & \multirow{10}{*}{$\begin{array}{l}61,560 \\
19,577\end{array}$} & \multirow{10}{*}{$\begin{array}{l}61,560 \\
81,137\end{array}$} \\
\hline 2 & 1,958 & 19,577 & 81,137 & & & \\
\hline 3 & ,914 & 9,141 & 90,277 & & & \\
\hline 4 & ,478 & 4,785 & 95,062 & & & \\
\hline 5 & ,238 & 2,378 & 97,440 & & & \\
\hline 6 & ,124 & 1,245 & 98,685 & & & \\
\hline 7 & ,068 & 681 & 99,366 & & & \\
\hline 8 & ,037 & 371 & 99,736 & & & \\
\hline 9 & 018 & 178 & 99,915 & & & \\
\hline 10 & ,009 & ,085 & 100,000 & & & \\
\hline
\end{tabular}

Método de Extração: Análise de Componente Principal.

Fonte: dados da pesquisa.

Na IES A foram gerados 2 fatores com percentual de informação para o modelo de 54, $79 \%$ para o primeiro fator e $18,48 \%$ para o segundo fator. Já na IES B, foram gerados três fatores com percentual de informação para o modelo de $54,87 \%$ para o primeiro fator, $17,89 \%$ para o segundo fator e $12,59 \%$ para o terceiro fator. Na IES C, foram gerados dois fatores com percentual de informação para o modelo de $61,56 \%$ para o primeiro fator e $19,57 \%$ para o segundo fator. Utilizou-se o método de rotação oblíqua Promax para analisar os coeficientes de correlação, visto que a rotação disponibiliza duas matrizes e uma matriz de estrutura, além da matriz fatorial, que delineiam padrões de intercorrelações entre as variáveis oblíquas.

Tabela 6 - Análise dos coeficientes de correlações com o método de Pattern Matrix

\begin{tabular}{cccccccccccc}
\hline IES & Dimensão & E1 & E2 & E3 & E4 & E5 & E6 & E7 & E8 & E9 & E10 \\
\hline \multirow{2}{*}{ A } & 1 & 0,206 & 0,725 & 0,725 & 0,209 & $\mathbf{0 , 9 1 3}$ & $\mathbf{0 , 9 5 9}$ & $\mathbf{0 , 6 3 5}$ & $\mathbf{0 , 9 2 0}$ & 0,399 & 0,353 \\
& 2 & $\mathbf{0 , 9 5 1}$ & 0,891 & $\mathbf{0 , 8 9 4}$ & $\mathbf{0 , 9 1 0}$ & 0,319 & 0,546 & 0,365 & 0,183 & $\mathbf{0 , 4 8 8}$ & $\mathbf{0 , 4 3 3}$ \\
\hline \multirow{3}{*}{ B } & 1 & $\mathbf{0 , 2 7 2}$ & $\mathbf{0 , 8 0 5}$ & $\mathbf{0 , 7 9 4}$ & $\mathbf{0 , 3 1 5}$ & $\mathbf{0 , 8 7 5}$ & $\mathbf{0 , 9 7 0}$ & $\mathbf{0 , 8 1 6}$ & $\mathbf{0 , 8 9 0}$ & 0,139 & 0,189 \\
& 2 & $-0,944$ & $-0,815$ & $-0,836$ & $-0,961$ & $-0,222$ & $-0,504$ & $-0,489$ & $-0,198$ & $-0,089$ & 0,047 \\
& 3 & 0,058 & 0,177 & 0,145 & $-0,011$ & 0,070 & 0,155 & 0,420 & 0,307 & $\mathbf{0 , 8 3 4}$ & $\mathbf{0 , 8 3 6}$ \\
\hline \multirow{2}{*}{ C } & 1 & $\mathbf{0 , 3 4 4}$ & $\mathbf{0 , 8 5 3}$ & $\mathbf{0 , 8 6 6}$ & $\mathbf{0 , 4 1 7}$ & $\mathbf{0 , 9 5 4}$ & $\mathbf{0 , 9 7 5}$ & $\mathbf{0 , 8 1 5}$ & $\mathbf{0 , 8 7 5}$ & 0,139 & $\mathbf{0 , 7 7 4}$ \\
& 2 & $-0,918$ & $-0,619$ & $-0,616$ & $-0,891$ & $-0,145$ & $-0,276$ & 0,021 & 0,201 & $\mathbf{0 , 4 3 1}$ & $-0,532$ \\
\hline
\end{tabular}

Método de Extração: Análise de Componente Principal.

Método de Rotação: Varimax com Normalização de Kaiser.

a. Rotação convergida em 3 iterações.

Fonte: dados da pesquisa.

De acordo com os critérios propostos por Hair et al. (1998), os itens E9 (ajuda externa) e E10 (revisão) na dimensão 3 da IES B e o item E9 (ajuda externa) da dimensão 2 da IES C foram excluídos ao considerar que apenas um fator não deve ser formado por dois ou mais itens. Neste sentido, a dimensão, obtidas pela análise conjunta, foi formada pelos itens E1 (autoavaliação), E2 (transformação e organização), E3 (estabelecimento de objetivos e planejamento), E4 (procura de informação), E8 e E10 (revisão) para a IES A. Na IES B, pelos 
Vinicius Costa da Silva Zonatto, Thiago Bruno de Jesus Silva, Patrinês Aparecida França Zonatto e Jéssica Andressa Krauss

itens E1(autoavaliação), E2 (transformação e organização), E3 (estabelecimento de objetivos e planejamento), E4 (procura de informação), E5 (tomada de apontamentos), E6 (estrutura ambiental), E7 (autoconsequência) e E8 (repetição e memorização). Por último, na IES C, pelos itens E1(autoavaliação), E2 (transformação e organização), E3 (estabelecimento de objetivos e planejamento), E4 (procura de informação), E5 (tomada de apontamentos), E6 (estrutura ambiental), E7 (autoconsequência), E8 (repetição e memorização) e E10 (revisão).

Para a realização desta investigação, estas dimensões foram intituladas de Estratégia Metacognitiva de Aprendizagem Autorregulada, sendo validadas de acordo com os procedimentos apresentados por Netemeyer et al. (2003), com as verificações de dimensionalidade, confiabilidade e convergência da análise fatorial. A Tabela 7 apresenta os resultados encontrados para a análise do teste de diferenças de médias quanto a adoção por parte dos alunos destas estratégias de aprendizagem autorregulada nas IES A, B e C.

Tabela 7 - Estratégias Metacognitivas de Aprendizagem Autorregulada de diferentes grupos

\begin{tabular}{|c|c|c|c|c|c|c|}
\hline \multirow[b]{2}{*}{ Estratégia } & \multirow[b]{2}{*}{ IES } & \multicolumn{2}{|c|}{ Teste de Levene } & \multicolumn{3}{|c|}{ Teste $t$} \\
\hline & & $\mathbf{F}$ & Sig. & $\begin{array}{c}\text { Erro Padrão } \\
\text { da Média }\end{array}$ & $\mathbf{T}$ & $\begin{array}{c}\text { Sig ( } 2 \\
\text { extremidades) }\end{array}$ \\
\hline \multirow{3}{*}{ EMC.02 } & IES A & 58,866 & 0,000 & 0,332 & 4,608 & 0,000 \\
\hline & IES B & 78,916 & 0,000 & 0,360 & 5,479 & 0,000 \\
\hline & IES C & 180,023 & 0,000 & 0,353 & 5,178 & 0,000 \\
\hline \multirow{3}{*}{ EMC.03 } & IES A & 40,128 & 0,000 & 0,253 & 4,691 & 0,000 \\
\hline & IES B & 44,511 & 0,000 & 0,278 & 5,447 & 0,000 \\
\hline & IES C & 104,177 & 0,000 & 0,260 & 5,512 & 0,000 \\
\hline \multirow{3}{*}{ EMC.05 } & IES A & 29,298 & 0,000 & 0,109 & 12,330 & 0,000 \\
\hline & IES B & 1,935 & 0,169 & 0,127 & 8,854 & 0,000 \\
\hline & IES C & 72,390 & 0,000 & 0,119 & 12,604 & 0,000 \\
\hline \multirow{3}{*}{ EMC.06 } & IES A & 102,183 & 0,000 & 0,235 & 13,433 & 0,000 \\
\hline & IES B & 134,718 & 0,000 & 0,255 & 12,810 & 0,000 \\
\hline & IES C & 105,959 & 0,000 & 0,295 & 11,361 & 0,000 \\
\hline \multirow{3}{*}{ EMC.07 } & IES A & 77,923 & 0,000 & 0,349 & 4,851 & 0,000 \\
\hline & IES B & 0,964 & 0,330 & 0,332 & 7,685 & 0,000 \\
\hline & IES C & 12,007 & 0,001 & 0,263 & 11,174 & 0,000 \\
\hline \multirow{3}{*}{ EMC.08 } & IES A & 0,014 & 0,908 & 0,098 & 24,233 & 0,000 \\
\hline & IES B & 22,854 & 0,000 & 0,118 & 21,232 & 0,000 \\
\hline & IES C & 2,810 & 0,099 & 0,146 & 13,701 & 0,000 \\
\hline EMC.10 & IES C & 71,050 & 0,000 & 0,195 & 4,442 & 0,000 \\
\hline
\end{tabular}

Nota: EMC 01 e EMC 09 excluídos na etapa de AFE.

Fonte: dados da pesquisa.

Os resultados apresentados na Tabela 7 indicam uma estatística t com nível de significância dos resultados menores que 0,05 para as estratégias metacognitivas de aprendizagem autorregulada EMC.02, EMC.03, EMC.05, EMC.06, EMC.07, EMC.08 e EMC.10. Assim, rejeita-se a hipótese nula de igualdade de médias para estes casos. As estratégias EMC.08 (repetição e memorização), EMC.06 (estrutura ambiental) e EMC.05 (tomada de apontamentos) foram as que alcançaram maior resultado no Teste $t$, o que sugere que tais variáveis melhor discriminam as estratégias predominantes adotadas por estes alunos no ensino de Contabilidade de Custos. A estratégia EMC.10 (procura de ajuda social) é peculiar para discriminar os alunos da IES C. Em contrapartida, a estratégia EMC.01 (autoavaliação) não conseguiu discriminar tal relação em nenhuma IES, o que indica que é comum na amostra.

Estes resultados reforçam as evidências encontradas em estudos anteriores, que indicam que discentes tendem a adotar diferentes estratégias de aprendizagem autorregulada 
Efeitos das estratégias de aprendizagem autorregulada na formação de inconsciente coletivo no conhecimento de contabilidade de custos

com a evolução da escala educativa (SCHLEIFER; DULL, 2009; BYRNE; FLOOD; WILLIS, 2009; BECKER, 2013; LIMA FILHO et al., 2015; SILVA et al., 2017; SILVA; BIAVATTI, 2018). Também revelam indícios de estratégias preferenciais utilizadas por discentes que cursaram a disciplina contabilidade de custos, comparativamente aqueles que ainda não cursaram, para a aprendizagem dos conteúdos abordados nesta disciplina. Portanto, as percepções identificadas a partir da análise estatística descritiva dos dados, apresentadas na Tabela 4, são confirmadas pela análise do Teste t.

Estes achados, se comparados a diferença de médias encontrada quando da análise sobre as concepções de diferentes grupos de alunos em relação aos métodos de custeio variável e por absorção, o que pode sugerir uma possível associação positiva entre o aumento nas estratégias de aprendizagem autorregulada e a mudança de concepção para a aderência ao custeio variável. Tais resultados sugerem uma motivação por parte da maioria destes alunos, para uma reflexão relacionada a quão adequado são estes dois conceitos para fins gerenciais, o que pode influenciar a não aceitação de práticas/conceitos contábeis que já foram comprovados como inadequadas para este fim.

Estas evidências permitem inferir que a adoção de diferentes metodologias de ensino e as percepções dos docentes para seu uso em sala de aula, observando o perfil da turma e suas preferências para o ambiente de ensino, tendem a influenciar a iniciativa dos alunos para a adoção de novas estratégias metacognitivas de aprendizagem autorregulada também no ensino de contabilidade de custos. Moos e Ringdal (2012) explicam que a percepção dos docentes sobre a aprendizagem tende a influenciar seu comportamento em sala de aula, determinando suas decisões sobre os métodos de ensino a serem adotados. Os professores que percebem os processos de ensino como acumulação de conteúdo e utilizam apenas instrução direta como estratégia de ensino, estarão limitando o desenvolvimento de estratégias metacognitivas de aprendizagem autorregulada por parte dos estudantes (MOOS; RINGDAL, 2012; SILVA; BIAVATTI; 2018), o que poderá refletir negativamente em sua aprendizagem.

A influência das estratégias de ensino na aprendizagem é reconhecida por diversos pesquisadores como um meio capaz de incentivar o desenvolvimento de atitudes independentes por parte dos alunos (ZIMMERMAN, 2001; LOMBAERTS et al., 2008; BECKER, 2011; MOOS; RINGDAL, 2012; SILVA et al., 2017). Tais ações contribuem para o amadurecimento profissional dos estudantes e o desenvolvimento de um pensamento mais reflexivo e crítico (BOEKAERTS; CORNO, 2005; BECKER, 2011; 2013). É por esta razão que os alunos, ao avançaram no curso de Ciências Contábeis tendem a melhor compreender as diferenças entre os métodos de custeio por absorção e variável.

De acordo com Silva e Biavatti (2018, p. 28), é importante que "os métodos de ensino utilizados pelos professores se aproximem de uma mescla entre a abordagem centrada no conteúdo e na aprendizagem". "Sua percepção sobre a aprendizagem demonstra predominância de característica da pedagogia tradicional em detrimento à andragogia" (SILVA; BIAVATTI, 2018, p. 29). Tais ações contribuirão para o amadurecimento dos alunos, pois os estudantes do ensino superior também precisam tornar-se independentes em sua aprendizagem, e agir para buscar meios (estratégias) para aprender.

Niiemi et al. (2014) defendem que os alunos devem receber orientação para o desenvolvimento de suas próprias estratégias metacognitivas de aprendizagem autorregulada. Mesmo reconhecendo que são difíceis de serem adquiridas por conta própria, é necessário que haja incentivo por parte dos professores, e dedicação por parte dos alunos, para sua promoção no ambiente instrucional. É por esta razão que segundo Niiemi et al. 
Vinicius Costa da Silva Zonatto, Thiago Bruno de Jesus Silva, Patrinês Aparecida França Zonatto e Jéssica Andressa Krauss

(2014), os professores devem apresentar um papel crucial na promoção da aprendizagem autorregulada dos estudantes.

Diante do exposto, em face as evidências encontradas nesta pesquisa, pode-se sugerir que o desenvolvimento da aprendizagem autorregulada, que implica em tornar o discente autônomo, independente e, portanto, responsável por sua formação acadêmica, pode levar determinados indivíduos a não persistirem com a aceitação de convicções relacionadas ao custeio por absorção, evidência que indica efeitos de uma aprendizagem autorregulada.

Apesar disto, é importante se considerar que tais efeitos não foram observados em toda a amostra analisada, o que indica que os efeitos de um inconsciente próprio (GUERREIRO; CASADO; BIO, 2001; SLOMSKI; BATISTA; CARVALHO, 2003, GUERREIRO; BIO; CASADO, 2004; SILVA et al., 2015), relacionado a contabilidade financeira, persistem entre alguns alunos e podem influenciar esta relação. Do mesmo modo, a que se considerar que outros aspectos presentes no ambiente de ensino também podem se constituir variáveis capazes de auxiliar no entendimento de tais resultados, como a formação docente (neste caso de professores doutores e pesquisadores vinculados a PPGs), as práticas de ensino por estes adotadas (relacionando a teoria com a prática) e a ênfase na abordagem dos conteúdos, entre outros fatores. Tais variáveis, se constituem oportunidade a realização de novos estudos.

\section{CONSIDERAÇÕES FINAIS}

Este estudo teve por objetivo investigar o inconsciente de diferentes grupos de alunos quanto a aceitação dos métodos de custeio variável e absorção, observando-se os potenciais efeitos do nível de estratégias metacognitivas de aprendizagem autorregulada utilizadas pelos alunos. Para tanto, desenvolveu-se uma pesquisa descritiva, com abordagem quantitativa, junto a 186 alunos do Curso de Ciências Contábeis de três IES localizadas no Estado de Santa Catarina. As instituições pesquisadas foram selecionadas por possuírem programas de pósgraduação stricto sensu, sendo o docente responsável pela disciplina de contabilidade de custos vinculado ao mesmo. Para a análise dos dados, utilizou-se os procedimentos estatísticos do teste de comparação de médias, análise descritiva e análise fatorial.

Os resultados encontrados evidenciam que nem todos os estudantes participantes da pesquisa mudaram sua postura ao longo do curso. No entanto, a formação docente contribuiu para que em todos os casos as médias relacionadas as diferentes concepções dos alunos aumentassem, indicando maior aderência aos preceitos do custeio variável após o curso da disciplina de contabilidade de custos, o que não foi observado entre todos os discentes participantes da pesquisa. Esta mudança também não foi percebida de maneira uniforme no grupo de estudantes que já possui experiência profissional na área contábil, resultado que sugere a existência de um tipo específico de inconsciente coletivo relacionado ao uso de sistemas de contabilidade baseados na contabilidade financeira.

Verificou-se que nem todos os estudantes que participaram da pesquisa possuem clara definição das principais diferenças existentes entre os métodos de custeio pesquisados. Estes resultados convergem aos achados encontrados no estudo desenvolvido por Silva et al. (2015). Tais evidências podem sugerem que a formação de diferentes inconscientes coletivos está associada de maneira distinta a compreensão adequada dos conceitos relacionados aos métodos de custeio variável e por absorção, sendo que: formação docente, práticas de ensino, ênfase na abordagem dos conteúdos e experiência profissional na área contábil são variáveis que contribuem para o entendimento de tais resultados.

Os achados desta pesquisa indicam que há uma mudança de comportamento dos alunos, quanto ao desenvolvimento de estratégias metacognitivas de aprendizagem 
Efeitos das estratégias de aprendizagem autorregulada na formação de inconsciente coletivo no conhecimento de contabilidade de custos

autorregulada. Ao cursarem a disciplina de contabilidade de custos, adotam estratégias adicionais, comparativamente as anteriormente utilizadas. Verificou-se haver diferenças significativas nas médias das estratégias investigadas entre os discentes que cursaram ou não a disciplina. Apesar disto, há alunos que não adotaram novas estratégias de aprendizagem autorregulada, assim como não modificaram suas percepções, as quais mantiveram-se mais aderentes aos conceitos do custeio por absorção.

A evolução na escala educativa influenciou a mudança nas concepções da maioria dos alunos nos três casos analisados, inclusive em parte daqueles que possuem um inconsciente específico relacionado ao uso de sistemas de contabilidade financeira, sendo as estratégias de repetição e memorização, estrutura ambiental e de tomada de apontamentos as que melhor discriminam tais diferenças. As evidências encontradas nesta pesquisa sugerem que a atuação de docentes pesquisadores, com formação em nível de doutorado, parece contribuir de maneira mais eficaz para a compreensão das diferenças entre tais conceitos, bem como suas limitações e potenciais contribuições quanto ao uso destes métodos para fins gerenciais.

Esta pesquisa apresenta algumas limitações, as quais não permitem a generalização dos resultados. No entanto, fornecem evidências adicionais que permitem uma melhor compreensão da formação de inconsciente coletivo no ensino da contabilidade de custos, bem como fornece evidências dos efeitos da formação de docentes (doutores) no ensino relacionado a tais conceitos. Também fornecem indícios dos efeitos do uso estratégias metacognitivas de aprendizagem autorregulada utilizadas pelos alunos nesta relação, temática ainda pouco investigada no ensino de contabilidade.

Como recomendações a estudos futuros, sugere-se a replicação desta pesquisa em outras instituições de ensino que possuem programas de pós-graduação stricto sensu, bem como junto a outras turmas em que professores apresentam formação em nível de mestrado e doutorado, a fim de se verificar o efeito de tal formação na mudança destas concepções. Nestes casos, a observância de práticas de ensino adotadas pelos docentes também pode revelar indícios de outro elemento de influência da compreensão adequada de tais conceitos. A experiência profissional dos discentes ainda precisa ser observada em novos estudos, uma vez que as evidências encontradas sugerem que esta pode influenciar a formação de um tipo de inconsciente específico. Do mesmo modo, outras variáveis não observadas em estudos anteriores podem ser inseridas nesta investigação, como os estilos motivacionais e de aprendizagem dos alunos. Tais oportunidades estimulam a realização de novos estudos.

\section{REFERÊNCIAS}

AGUIAR, José Hilton Santos. Análise demográfica e acadêmica da autorregulação da aprendizagem de estudantes de Ciências Contábeis de IES em Salvador. Revista de Educação e Pesquisa em Contabilidade (REPeC), v. 13, n. 2, 2019.

BECKER, L. L. Self-Regulated Learning in an Introductory Undergraduate Accounting Course. 2011. (179 f.) Tese (Doutorado em Educação em Liderança), Universidade Estadual do Leste de Tennessee, EUA, 2011.

BECKER, L. L. Self-Regulated Learning Interventions in the Introductory Accounting Course: An Empirical Study. Issues in Accounting Education, v. 28, n. 3, p. 435-460. 2013. DOI: https://doi.org/10.2308/iace-50444. 
Vinicius Costa da Silva Zonatto, Thiago Bruno de Jesus Silva, Patrinês Aparecida França Zonatto e Jéssica Andressa Krauss

BLACK, W. H. The activities of the pathways commission and the historical context for changes in accounting education. Issues in Accounting Education. v. 27, n. 3, p. 601-625, 2012. DOI: https://doi.org/10.2308/iace-50091

BOEKAERTS, M.; CORNO, L. Self-regulation in the classroom: A perspective on assessment and intervention. Applied Psychology, v. 54, n. 2, p. 199-231, 2005. DOI:

https://doi.org/10.1111/j.1464-0597.2005.00205.x

BRADSHAW, S.; STORM, L. Archetypes, symbols and the apprehension of meaning. International journal of Jungian studies. V. 5, n. 2, p. 154-176, 2013. DOI: https://doi.org/10.1080/19409052.2012.685662

BYRNE, M.; FLOOD, B.; WILLIS, P. An Inter-Institutional Exploration of the Learning Approaches of Students Studying Accounting. International Journal of Teaching and Learning in Higher Education. V.20, n. 2, p. 155-167. 2009.

BUTLER, Maureen Gibson et al. Do Your Students Know What They Don't Know? An Accounting Competencies Strategy Do Your Students Know What They Don't Know? Issues in Accounting Education.

CHANG, H. M.; IVONIN, L.; DÍAZ, M.; CATALÀ, A.; CHEN, W.; RAUTERBERG, M. From mythology to psychology: Identifying archetypal symbols in movies. Technoetic Arts. v. 11, n. 2, p. 99-113. 2013. DOI: https://doi.org/10.1386/tear.11.2.99_1

CHO, M. H.; SHEN, D. Self-regulation in online learning. Distance education. v. 34, n. 3, p. 290-301. 2013. DOI: https://doi.org/10.1080/01587919.2013.835770

COETZEE, S. A.; SCHMULIAN, A. A critical analysis of the pedagogical approach employed in an introductory course to IFRS. Issues in Accounting Education. v. 27, n. 1, p. 83-100, 2012. DOI: https://doi.org/10.2308/iace-10220

COSTA, F.; CRUZ, A. P. C.; ESPEJO, M. M. D. S. B. Paradoxo na utilização de artefatos contábeis gerenciais: discussão sobre a influência de fatores inconscientes inspirada em conceitos preconizados pela psicologia analítica. Revista Universo Contábil. V. 7, n. 3, p. 5976. 2011. DOI: http://dx.doi.org/10.4270/ruc.20117

DAGOSTINO, G. B. Formação de professores em processos andragógicos de ensino e aprendizagem. In: XVI ENDIPE-Encontro Nacional de Didática e Práticas de Ensino-Editora: Junqueira e Marin, UNICAMP-Campinas, p. 1-12. 2012, SP. Anais....SP, 2012.

DELEN, E.; LIEW, J.; WILLSON, V. Effects of interactivity and instructional scaffolding on learning: Self-regulation in online video-based environments. Computers \& Education, V.78, p. 312-320. 2014. DOI: http://doi.org/10.1016/j.compedu.2014.06.018

DEMETRIOU, A. Organization and development of self-understanding and self-regulation. Toward a general theory, In M. Boekaerts, P. R. Pintrich, \& M. Zeidner (Eds.), Handbook of self-regulation (p. 209-251). Academic Press. 2000. DOI: https://doi.org/10.1016/B978012109890-2/50036-6. 
Efeitos das estratégias de aprendizagem autorregulada na formação de inconsciente coletivo no conhecimento de contabilidade de custos

ESPEJO, M. M. D. S. B.; COSTA, F.; CRUZ, A. P. C.; ALMEIDA, L. B. Uma análise crítico-reflexiva da compreensão da adoção dos artefatos de contabilidade gerencial sob uma lente alternativa a contribuição de abordagens organizacionais. Revista de Contabilidade e Organizações, v.3, m. 5, p. 25-43. 2009. DOI: https://doi.org/10.11606/rco.v3i5.34730

FABER, M. A.; MAYER, J. D. Resonance to archetypes in media: There's some accounting for taste. Journal of Research in Personality, v. 43, n. 3, p. 307-322. 2009. DOI: https://doi.org/10.1016/j.jrp.2008.11.003

FERNANDES, F. C.; ZONATTO, V. C. S. Neuroaccounting: reinterpretando resultados de pesquisas em Contabilidade Gerencial. Ciências \& Cognição, v. 18, n. 1, p. 33-45. 2013.

FLAVELL, J. H. Metacognitive aspects of problem solving. In L. B. Resnick (Ed.), The nature of intelligence, v. 7, n. 9. p. 231-235. 1976.

GUERREIRO, R.; CASADO, T.; BIO, S. R. Algumas reflexões sobre os arquétipos e o inconsciente coletivo na contabilidade de custos: um estudo exploratório. Revista de Contabilidade CRC-SP. São Paulo, p. 04-21. 2001.

GUERREIRO, R.; BIO, S. R.; CASADO, T. Some reflections on the archetypes in cost accounting: an exploratory study. Journal of Applied Management Accounting Research, $\mathrm{v}$. 2, n. 1, p. 41, 2004.

GUERREIRO, R.; FREZATTI, F.; CASADO, T. Em busca de um melhor entendimento da contabilidade gerencial através da integração de conceitos da psicologia, cultura organizacional e teoria institucional. Revista Contabilidade \& Finanças, v. 17, n.1, p.7-21, 2006. DOI: https://doi.org/10.1590/S1519-70772006000400002

GUERREIRO, R.; CORNACHIONE JR, E. B.; SOUTES, D. O. A utilização de artefatos modernos de contabilidade gerencial por empresas brasileiras. Revista Contabilidade \& Finanças-USP, v. 22, n. 55, p. 5-22, 2011. DOI: https://doi.org/10.1590/S1519-70772011000100006

JUNG, C. G. The concept of the collective unconscious. Collected works, v. 9, n.1, p. 42. 1936.

Psicologia do inconsciente. Petrópolis: Vozes. 1995.

LIMA FILHO, R. N.; DE LIMA, G. A. S. F.; BRUNI, A. L. Self-regulated learning in accounting: diagnosis, dimensions and explanations. Brazilian Business Review, v. 12, n.1, p. 36, 2015. DOI: http://dx.doi.org/10.15728/bbr.2015.12.1.2

LIU, Yingwei et al. Study on Chinese Brand cultural archetype: theory building and crosscultural comparison. Journal of Contemporary Marketing Science, 2020.

MEGLIORINI, E.; GUERREIRO, R. Conceitos de mensuração utilizados pelas empresas produtoras de bens de capital sob encomenda. In Anais... 4ํ Congresso de Controladoria $e$ Contabilidade. 2004. 
Vinicius Costa da Silva Zonatto, Thiago Bruno de Jesus Silva, Patrinês Aparecida França Zonatto e Jéssica Andressa Krauss

MOOS, D. C.; RINGDAL, A. Self-regulated learning in the classroom: A literature review on the teacher's role. Education Research International, v. 2012, 2012. Article ID 423284, 15 pages. DOI: https://doi.org/10.1155/2012/423284

NETEMEYER, R. G.; BEARDEN, W. O.; SHARMA, S. Scaling procedures: issues and Applications. SAGE, 2003.

PAPAZOGLOU, E. M. Development of the teacher as metacognitive agent. 2010. (147 f.) Tese. (Doctor of Arts), College of Graduate and Professional Studies. Franklin Pierce University, EUA 2010.

PIAGET, J. A formação do símbolo na criança: Imitação, jogo e sonho, imagem e representação (A. Cabral, Trad.). Rio de Janeiro, RJ: Zahar. 1978.

RAGOSTA, $P$. The effectiveness of intervention programs to help college students acquire self-regulated learning strategies: A meta-analysis. City University of New York, 2010.

ROSÁRIO, P. Diferenças processuais na aprendizagem: avaliação alternativa das estratégias de auto-regulação da aprendizagem. Psicologia, Educação e Cultura, v. 5, n. 1, p. 87-102. 2001.

ROSÁRIO, P. Estudar o estudar: As (Des) venturas do Testas. Porto: Porto Editora. 2004.

ROSÁRIO, P. Variáveis cognitivo-motivacionais na aprendizagem: as abordagens ao estudo em alunos do Ensino Secundário. Braga: Universidade do Minho (tese de doutoramento). 1999.

SANTOS, C. C. Individuação junguiana. Sarvier. 1976.

SCHLEIFER, L. L.; DULL, R. B. Metacognition and performance in the accounting classroom. Issues in Accounting Education, v. 24, n.3, p. 339-367. 2009. DOI: http://doi.org/10.2308/iace.2009.24.3.339.

SILVA, T. B. J.; BIAVATTI, V. T. Estratégia metacognitiva de aprendizagem autorregulada, percepção docente sobre a aprendizagem e métodos educacionais em contabilidade.

Revista Contemporânea de Contabilidade, v. 15, n. 37, p. 03-33. 2018. DOI:

http://dx.doi.org/10.5007/2175-8069.2018v15n37p3

SILVA, T. B. J.; LAY, L. A.; BIAVATTI, V. T.; HEIN, N.; ZONATTO, V. C. S. As Estratégia de Aprendizagem Autorregulada (SRL) no Ensino EAD de Contabilidade. Revista de Educação e Pesquisa em Contabilidade (REPeC), v. 11, n. 1, art. 5, p. 90-109, jan./mar, 2017. DOI: https://doi.org/10.17524/repec.v11i1.1412

SILVA, T. B. J.; LAY, L. A.; PAMPLONA, E.; ZONATTO, V. C. S. Inconsciente coletivo no conhecimento de contabilidade de custos: uma abordagem a partir da Psicologia Analítica de Jung e os métodos de custeio variável e por absorção. Enfoque: Reflexão Contábil, v. 34, n.2, p. 123-142, 2015. DOI: 10.4025/enfoque.v34i2.28462

SLOMSKI, V.; BATISTA, I. V. C.; DE CARVALHO, E. M. Os métodos de custeio variável e por absorção e o inconsciente coletivo na contabilidade de custos. Revista de Contabilidade do 
Efeitos das estratégias de aprendizagem autorregulada na formação de inconsciente coletivo no conhecimento de contabilidade de custos

Mestrado em Ciências Contábeis da UERJ, v. 8, n.1, 2003. DOI:

https://doi.org/10.12979/rcmccuerj.v8i1.5606

TUYSUZOGLU, B. B. An investigation of the role of metacognitive behavior in self-regulated learning when learning a complex science topic with a hypermedia learning environment. 2011. (64 f) Tese de Doutorado. The University of North Carolina at Chapel Hill. 2011.

XU, M.; BENSON, S. N. K.; MUDREY-CAMINO, R.; STEINER, R. P. The relationship between parental involvement, self-regulated learning, and reading achievement of fifth graders: $A$ path analysis using the ECLS-K database. Social Psychology of Education, v. 13, n.2, p. $237-$ 269, 2010. DOI: https://doi.org/10.1007/s11218-009-9104-4

ZIMMERMAN, B. J.; PONS, M. M. Development of a structured interview for assessing student use of self-regulated learning strategies. American educational research journal, v.23, n.4, p. 614-628, 1986. DOI: http://dx.doi.org/10.1037/10213-000 ; SCHUNK, D. H. (Eds.). Self-regulated learning and academic achievement: Theoretical perspectives. Routledge. 2001. 